\title{
Marcas da competitividade
} 1 abertura progressiva das fronteiras nacionais criou um ambiente comercial em que proliferam em abundância opções deprodutos eserviços para o consumidor global. Empresase países competitivos são os que conseguem tornar seus produtos eserviços atrativos e diferenciados aos olhos desse exigente consumidor. 0 artigo discute a importância da internacionalização de uma marca forte do país no exterior ea contribuição de empresas nacionais pioneiras na acirrada disputa pelas vitrines do mercado mundial.

por Ismael Rocha e Maurício Turra Ponte ESPM

Q uando tratamos da competitividade de um país, é quase obrigatória a menção ao estado de saúde de suas exportações. Com base nela, o país angaria recursos externos preciosos e estimula seu próprio desenvolvimento em uma espécie de reação em cadeia. N esse sentido, o tema desperta preocupações constantes de governos e empresas, sobretudo com respeito aos fatores capazes de gerar um bom volume - associado à qualidade - de exportações.

N este artigo, em particular, analisamos o papel da internacionalização de marcas de produtos brasileiros no estímulo a suas exportações e, conseqüentemente, sua competitividade. Defendemos que a escassez de marcas 
brasileiras mundiais fortes é fator crítico que inibe uma maior participação do país no comércio mundial. Em perspectiva diferente da que se tornou popular a partir da publicação do livro da jornalista norte-americana Naomi Klein, No logo, 0 artigo postula que, sem marcas fortes, não há marketing, tampouco estratégias que possam adicionar algum tipo de diferencial aos produtos de nossas empresas. Felizmente, conforme demonstrado aqui, há algumas experiências bem-sucedidas nesse campo que podem trazer importantes lições.

Perfil das exportações. No ano de 2004, o Brasil obteve um avanço significativo em suas exportações, conseguindo ampliá-las em 32\% em relação ao ano anterior. Isso representa algo em torno de $9 \%$ de crescimento do comércio global. Mesmo assim, a participação brasileira representa modesto $1,1 \%$ do conjunto desse comércio, ocupando a 26a posição. mos uma forte dependência da produção de commodities (ver Figura), ou seja, produtos de margens estreitas e que estão à mercê de subsídios internacionais. Se somarmos a tudo isso as dificuldades burocráticas que as empresas exportadoras do país têm de enfrentar, a falta de melhor preparo das pequenas e médias e o foco prioritário no mercado interno por parte do empresariado brasileiro, teremos um quadro pouco estimulante em relação à maior participação do país no mercado internacional.

O valor da marca. Não apenas características como as anteriormente destacadas afetam nosso desempenho no mercado externo. Em uma época em que a homogeneidade tecnológica nivelou muitas empresas, resta aos ativos intangíveis, em particular às marcas, a responsabilidade de tornar a empresa competitivamente diferenciada. Vejamos melhor como isso ocorre.

Para al guns pesquisadores do assunto, a marca adiciona ou subtrai valor de um produto ou serviço mediante a leal dade que permite estabelecer com o consumidor, a notoriedade ou conhecimento que permite a criação de novas linhas de produtos, a qualidade transmitida e mediante as associações realizadas pelo público consumidor e que a distinguem entre as outras. $E$, no caso de marcas que competem em mercados internacionais, há ainda um fator adicional, a

Apesar do esforço do governo federal em alavancar as exportações por meio da ampliação do número de países importadores e da pauta de produtos, ainda hoje o país depende significativamente da participação de poucas indústrias competitivas. Indústrias como mineração, siderurgia, produtos agrícolas, alimentos e papel e celulose souberam tirar proveito da riqueza natural do país, bem como de uma boa economia de escala e, não obstante a pesada carga tributária do país e o alto custo de capital, estão dando sinais de progresso.

Em uma visão geral, no entanto, o fato é que, não obstante a heterogeneidade do parque industrial brasileiro e da diversidade dos produtos aqui fabricados, mante- saber, a percepção que os consumidores possuem do país de origem e do fabricante do produto.

Em particular neste último caso, diversos estudos buscam analisar quais são as influências do país de origem sobre a decisão de compra de consumidores em centros internacionais. 0 pressuposto é que estes últimos criam estereótipos acerca das características dos países de origem, que compõem o julgamento sobre a qualidade do produto e, por conseqüência, sobre a decisão de compra.

Essa é a tese defendida, por exemplo, por Shooler, um pesquisador que, já em 1965, notou que os consumidores avaliavam produtos com mesmos atributos, de forma distinta, unicamente devido à percepção sobre o país 
de origem. Ainda de acordo com esse pesquisador, e outros sobre o mesmo tema, os consumidores tendem a favorecer produtos de países que possuem o prestígio de serem desenvolvidos, pois tal percepção associa-se positivamente à qualidade do produto.

Nesse sentido, podemos destacar como comuns no imaginário dos consumidores mundiais al guns estereótipos característicos. Por exemplo, como aponta Gianetti da Fonseca, em seu artigo 0 Brasil e sua imagem no exterior, ninguém duvida que a imagem da Alemanha está associada aos conceitos de alta precisão, modernas tecnologias e alta confiabilidade; a França, à imagem de sofisticação, produtos de alto luxo e valor estético; já a Itália destaca-se pela imagem de seu criativo e elegante design em vários campos da indústria de bens de consumo; o Japão tem sua imagem associada à miniaturização e à inventividade no setor eletroeletrônico; e os Estados Unidos têm como imagem principal a funcional idade e a tecnologia aplicada nos vários segmentos de sua pujante e diversificada economia. E o Brasil, qual sua imagem no exterior?

Café e banana. São escassos os estudos que analisam,
A pesquisa aponta ainda que o Brasil possui aspectos positivos associados à simpatia de seu povo, à musicalidade, à ginga, à criatividade e à beleza de seus recursos naturais. São esses fatores que nos distinguem de outras nações, embora não auxiliem na venda de produtos que exigem maior diferenciação tecnológica. Antes, o país é percebido como sendo desatual izado nesse sentido, cujos produtos não são relacionados com inovação, mas sim com baixa qualidade e pouca confiabilidade.

É interessante destacar que esta pesquisa pode nos ajudar a entender por que várias empresas nacionais com maior diferenciação tecnológica têm dificuldade na introdução de seus produtos no mercado internacional. Aparentemente, nem mesmo a expertise brasileira em áreas como tecnologia bancária e el eitoral, produção de aeronaves, pesquisas sobre genoma e, mais recentemente, nanotecnologia, possibilita vantagens competitivas para essas áreas. Nesse sentido, a pesquisa confirma constatações comuns como a de que o país é associado à natureza e ao calor humano do povo, e não à inteligência produtiva encontrada em certos nichos.

Corroboram esta pesquisa os dados encontrados em com precisão, a imagem do país vista de fora. No entanto, alguns podem ser aqui citados. Por exemplo, o da agência de propaganda Young e Rubicam. A agência realizou em 2000 uma pesquisa de opinião com trinta mil consumidores em todo o mundo e constatou que o Brasil é percebido a partir de atributos como alta diferenciação, categoria que distingue um país de outros; relevância, que identifica a importância dada ao país; vital idade da marca Brasil. Esse conceito relaciona-se com outros atributos, como a estima e o conhecimento que os consumidores têm pelo Brasil. O u seja, isso significa que o país é lembrado por eles e percebido favoravel mente.

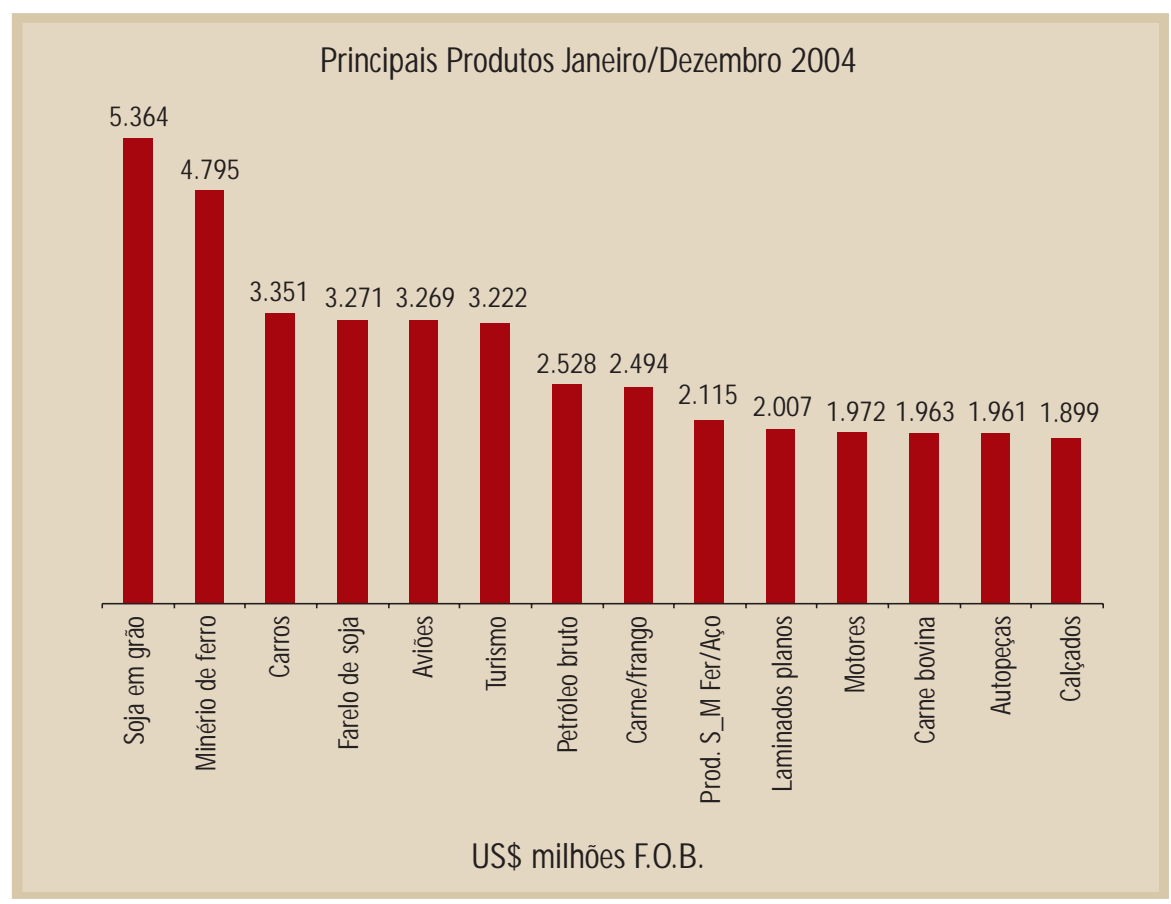

Figura: Exportações Brasileiras Fonte: $\mathrm{BCB}$ 
outro estudo encomendado pela Confederação Nacional do Transporte (CNT), realizado em 2001. Nele, foram entrevistados nove mil consumidores de 22 países, aponsuas praias, futebol, alegria e cordialidade de seu povo. Ao mesmo tempo, os produtos brasileiros mais facilmente identificados são o café e a banana. 0 verde-e-amarelo do país aparece nos centros mundiais, como na famosa Galeries Lafayette, Paris, com produtos como sucos, alimentos, chás, roupas e calçados. tando que o Brasil continua conhecido principalmente por

nar produtos tão variados é um risco para o desenvolvimento de associações que fortaleçam os benefícios percebidos pelo consumidor internacional. Ao contrário, o governo deveria restringir o uso do selo a produtos que criem sinergia entre si eque val orizem aspectos da brasilidade, ao mesmo tempo em que deve ampliar seus esforços em ações que valorizem as iniciativas das indústrias, relacionando os diferenciais específicos de seus produtos e não apenas fazendo uso de anúncios pontuais. Vamos destacar, a seguir, algumas empresas brasileiras do segmento de moda e cosméticos que ilustram como ações integradas e planejadas podem ser sustentadas por meio da valorização de suas marcas.

\section{associados à si mpatia de seu povo, à}

\section{musicalidade, à ginga, à criatividade e à}

\section{beleza de seus recursos naturais, embora} estes não auxiliem na venda de produtos que exigem maior diferenciação tecnológica.
Made in Brazil . Algumas empresas brasileiras têm conseguido bons resultados em suas iniciativas internacionais, mesmo sofrendo algumas limitações como porte, diferenciação tecnológicade produtos ou uma participação de mercado com limitados ganhos em escala. Desse modo, o que empresas como
A Marca Brasil. Algumas iniciativas locais, de governo e empresas, vêm sendo organizadas com o intuito de mudar a imagem do país no exterior. Em primeiro lugar, vejamos a iniciativa denominada de Marca Brasil. 0 projeto, lançado em fevereiro deste ano pelo governo federal, tornou-se importante objeto para a promoção comercial do país no exterior e, como destacou em público o ministro Luis Fernando Furlan, "a ausência de conhecimento sobre o Brasil ou seu relacionamento à tril ogia samba, café e Pelé não produz resultados eficazes para as empresas".

Depois de pouco mais de cinco meses, já é possível observar alguns resultados. Existem hoje 597 solicitações de uso da Marca Brasil, englobando desde aviões, cafés, chás, geléias e outros produtos alimentícios, bolas de futebol, cangas de praia, além de material promocional de operadoras de turismo e órgãos oficiais do governo.

No entanto, em nosso modo de ver, a Marca Brasil não deve ser entendida unicamente como um selo ou logotipo a ser estampado nos produtos comercializados fora. É preciso haver foco na realização dessa ação. Relacio-
Natura, 0 Boticário, Rosa Chá e Alpargatas/H avaianas têm a nos ensinar? Vejamos a seguir cinco pontos comuns que parecem estar na base desses bons resultados.

0 primeiro ponto em comum nessas experiências de internacionalização é a diferenciação na formulação dos produtos ou na matéria-prima utilizada. A Havaianas mantém sigilo absoluto sobre a composição de sua borracha; a Natura e o Boticário utilizam em seus produtos ingredientes naturais da flora brasileira, sobretudo da Amazônia que despertam a atenção dos consumidores internacionais pela excentricidade. Por sua vez, a Rosa Chá diferencia-se pela criação de valor por meio de design sofisticado e de sua marca, transparecendo a própria essência da Marca Brasil no que diz respeito à idéia de integração com a natureza.

0 segundo refere-se ao fato de todas essas empresas serem líderes no seu segmento de atuação no Brasil. Por exemplo, a Natura e 0 Boticário são as duas maiores empresas brasileiras de produtos de beleza, um mercado que, em 2004, movimentou a expressiva cifra de $R \$ 12,1$ bi- 
Ihões. Já as Havaianas, produzidas pela Alpargatas, tornaram-se um ícone nacional; e, por fim, a Rosa Chá consagrou-se pela atuação em um nicho em que tem representação exclusiva na venda de biquínis, um segmento pulverizado em centenas de pequenos fabricantes artesanais.

0 terceiro ponto que está na origem da internacionalização das marcas dessas empresas é a acumulação de experiência anterior em processos de internacionalização. A Alpargatas iniciou em 1994 suas exportações para alguns países da América do Sul; somente a partir de 2001 a empresa reestruturou sua área de trade, o que permitiu a ampliação de seus negócios para mais de cinqüenta países. Em 1997, a Rosa Chá entrou no mercado norte-americano por meio de lojas multimarcas e, em 2002, expandiu sua marca para o mercado europeu. A Natura começou pelo Chile, na década de 1980 e a partir daí expandiu sua atuação para Argentina, Peru e Bolívia. 0 Boticário inaugurou sua primeira loja fora do Brasil, no Shopping das Amoreiras, localizado na capital portuguesa, e hoje possui a maior rede de franquias em número de revendas em Portugal, com 69 lojas, além de 399 pontos de venda distribuídos pelo Japão.

0 quarto ponto éuma estratégia seletiva de distribuição. As Alpargatas são encontradas em canais de vendas como Sacks Fifth Avenue, de Nova York, a Selfridge's, de Londres, e as Galeries Lafayette, de Paris. A N atura estreou em Paris com uma loja própria, a Maison Natura, instalada na charmosa Carrefour de la Croix-Rouge, diferentemente de seu histórico modelo de venda direta. 0 Boticário permaneceu fiel a seu modelo de franquia adotado no Brasil, ao passo que a Rosa Chá atua com um modelo híbrido envolvendo lojas próprias e lojas multimarcas criteriosamente selecionadas.

0 último ponto refere-se ao uso de imagens associadas a determinados personagens e valores. A Havaianas calça a atriz Nicole Kidman, a modelo N aomi Campbell e a princesa Stéphanie de M ônaco. Gity Monsef, diretora de criação do Zandra Rhodes Museum, respeitado museu de moda de Londres, afirmou que as Havaianas são "a essência da simplicidade sexy" e ostentam "um design maraviIhosamente clean", o que pode ser comprovado observando sua alta utilização pelos jovens no quente verão europeu de 2005. 0 Boticário e Natura transmitem imagens relacionadas à natureza, qualidade de vida e respeito ao meio ambiente. Alpargatas e Rosa Chá transmitem imagens que valorizam a sinuosidade das formas, vivacidade de cores e a sensualidade da mulher brasileira.

Novos bandei rantes. Encerramos este artigo com lições que podem ser generalizadas a partir dos exemplos aqui discutidos para outros setores de indústrias no Brasil, tendo em vista a internacionalização de nossas marcas e o conseqüente incremento de competitividade que esta ação propicia.

Em primeiro lugar, é notório que a imagem do país tem sido cada vez mais utilizada em diversos outros setores. Seria interessante se esses setores, à luz das experiências das quatro empresas destacadas neste texto, soubessem associar a suas marcas os fortes atributos de nossa cultura e valores, tal como percebidos pelo resto do mundo. Em particular, exotismo, al egria, matérias-primas exclusivas e desenvolvimento sustentável de recursos naturais representam certamente um amplo conjunto de oportunidades para disseminação de suas marcas lá fora.

Em segundo lugar, pensamos ser imprescindível às empresas atentarem para a necessidade de investir a fim de que suas marcas cheguem às vitrines internacionais. Evidências obtidas pelos casos da Natura, Rosa Chá, Alpargatas e 0 Boticário são inquestionáveis para ampliar as fronteiras de negócios além do território doméstico. Essas empresas, ao menos por enquanto, podem ser exceção, mas também exemplo de combinações oportunas entre planejamento, investimento em pesquisa e em inovação, visão estratégica e de longo prazo, gestão financeira saudável e, enfim, capacidade de olhar para o próprio país para, depois, olhar para fora. Seriam os novos bandeirantes do século XXI.

Ismael Rocha

Prof. de Marketing da ESPM

Mestrando em Ciências da Religião na Universidade Mackenzie E-mail: irocha@espm.br

Maurício Turra Ponte

Prof. de Marketing da ESPM

M estrando em Administração na PUC-SP

E-mail: mturra@espm.br 